\title{
EFFECT OF TOPOGRAPHY ON HYGROMETER READINGS
}

\author{
By J. C. MAcleod
}

\author{
Dominion Forest Service, Ottawa, Ontario
}

In an article entitled, "Effect of Site Conditions on Hygrometer Readings", which appeared in the March, 1947, issue of "The Forestry Chronicle," the writer discussed the effect of site upon the measurement of relative humidity with Mason-type hygrometers. The two other factors with which forest-fire weather observers are most often concerned in setting up hygrometer shelters are local topography and the presence of lakes, rivers and swamps. Observations of the effect on relative humidity of such water are presently being made, but insufficient data have been obtained to show conclusive results at this time.

A forest-weather station in Manitoba visited in June, 1948, offered an excellent opportunity for observing the effect of certain topographic features on relative humidity. The officer in charge of the station advised that he had some doubts that he was obtaining readings which were fully representative of his locality. The station hygrometer shelter was located in an area where mists often formed when there was no mist to be seen elsewhere in the neighbourhood, and the officer felt that the relative humidity readings might be running consistently too high.

The hygrometer shelter was in the approximate centre of a large clear space having a grass ground cover. The site was slightly lower than most of the surrounding territory and the soil usually appeared to be quite damp. Since it was believed that a hygrometer at this site might be unduly affected, it was decided to try it out with the use of two hygrothermographs. One of these instruments was set up in a shelter within a few feet of the hygrometer shelter, and the other on the top of a relatively high rock outcrop some 200 yards to the north, which formed a ridge running east and west. The upper site was about 40 feet higher than the lower and was in a most exposed position. In fact it was too high above the surrounding country and too exposed to be considered suitable for normal use. However, it was chosen as being the most exposed and mistfree location reasonably close to the hygrometer site.

The hygrothermographs had been carefully calibrated immediately before being set out and were run for four weeks, being interchanged at the end of each week; thus each instrument had two alternate weeks at each site. The instruments were checked at least once a week with a sling pschrometer, but no adjustments were required. If any instrumental error did occur, the effects of practically all of it would be cancelled by the interchanging.

Although the investigation was concerned primarily with relative humidity, temperature data were also tabulated. Maximum and minimum relative humidities and temperatures were noted for the average two-hour per- 
iod each day rather than for the absolute (or momentary) highs and lows. For the 28-day period, the averages were as follows:

\begin{tabular}{|c|c|c|c|c|}
\hline & \multicolumn{4}{|c|}{ Average Two-Hour } \\
\hline & Relati & $\begin{array}{l}\text { aidity } \\
\text { at }\end{array}$ & & \\
\hline & Max. & Min. & Max. & Min. \\
\hline wer Site & 98.1 & 53.8 & 75.6 & 54.1 \\
\hline Upper Site & 98.0 & 51.9 & 76.1 & 57.4 \\
\hline
\end{tabular}

From this it will be seen that the lower site averaged only 1.9 per cent higher in minimum relative humidity than the upper, while there was practically no difference between the two sites in the maximum relative humidity averages. Although the average minimum relative humidity for the test period was somewhat higher than would be expected for the summer season, there were a few days on which the minimums were in the thirties, at which times the differences between the sites were not above the average.

The degree of agreement between the minimum relative humidities of the sites is shown in the following:

Min. relative humidity difference not more than $1 \%, 29 \%$ of the time

Min. " " " " " " " " $2 \%, 57 \%$ " " "

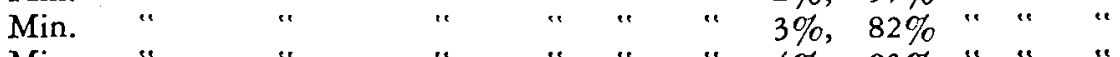

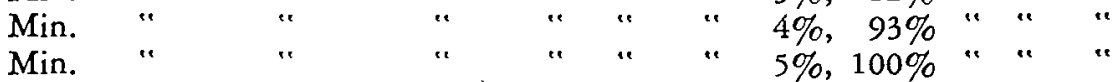

Considering the accuracy required in danger rating systems, and the method of measurement normally used (Mason-type hygrometers) it may be considered that, for all practical purposes, there was little or nothing to choose between the two sites in the determination of relative humidity.

So far as temperature measurement was concerned, the table shows that the average two-hour maximum differed by only half a degree between the two sites. The greatest maximum temperature difference was three degrees and there was only one instance of this.

While minimum temperatures are seldom, if ever, used in determining the danger index, the fact that the minimum temperatures at the upper site were somewhat higher than those at the lower site (greatest difference in test period, eight degrees) may account, in part, for the occurrence of mist in the evenings and mornings at the lower site. The cool air, draining into the lower land from the ridges, condenses the water vapour, thus forming mist. Although the atmosphere in the surrounding areas contains just as much water vapour, it is not cooled quickly enough to condense the latter into visible form.

It is indicated in the foregoing that topography, other than in mountainous areas does not, so far as forest fire protection requirements are concerned, greatly affect the measurement of relative humidity. Probably the greatest effect that topography has in this connection is in obstructing the free movement of air in the immediate vicinity of the hygrometer. 